\title{
Extending the Frontiers Beyond Thermal Ablation by Radiofrequency Ablation: SBRT, Brachytherapy, SIRT (Radioembolization)
}

\author{
Peter Hass $^{a, b}$ Konrad Mohnike ${ }^{b, c}$

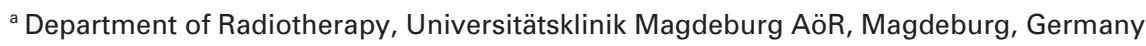 \\ ${ }^{\mathrm{b}}$ International School of Image-Guided Interventions/Deutsche Akademie für Mikrotherapie, Magdeburg, Germany \\ ${ }^{\mathrm{c}}$ Department of Radiology and Nuclear Medicine, Universitätsklinik Magdeburg AöR, Magdeburg, Germany
}

\section{Keywords}

Minimally invasive interventions · Radiofrequency ablation . RFA - Stereotactic body radiation therapy - SBRT .

Interstitial brachytherapy - iBT . Selective internal radiation therapy · SIRT

\section{Summary}

Metastatic spread of the primary is still defined as the systemic stage of disease in treatment guidelines for various solid tumors. This definition is the rationale for systemic therapy. Interestingly and despite the concept of systemic involvement, surgical resection as a local treatment has proven to yield long-term outcomes in a subset of patients with limited metastatic disease, supporting the concept of oligometastatic disease. Radiofrequency ablation has yielded favorable outcomes in patients with hepatocellular carcinoma and colorectal metastases, and some studies indicate its prognostic potential in combined treatments with systemic therapies. However, some significant technical limitations apply, such as size limitation, heat sink effects, and unpredictable heat distribution to adjacent risk structures. Interventional and non-invasive radiotherapeutic techniques may overcome these limitations, expanding the options for oligometastatic patients and cytoreductive concepts. Current data suggest very high local control rates even in large tumors at any given location in the human body. The article focusses on the characteristics and possibilities of stereotactic body radiation therapy, interstitial high-dose-rate brachytherapy, and Yttrium-90 radioembolization. In this article, we discuss the differences of the technical preferences as well as their impact on indications. Current data is presented and discussed with a focus on application in oligometastatic or cytoreductive concepts in different tumor biologies.

\author{
Schlüsselwörter \\ Minimalinvasive Interventionen - Radiofrequenzablation . \\ RFA - Stereotaktische (Körper-)Radiotherapie - SBRT . \\ Interstitielle Brachytherapie · iBT . Selektive interne \\ Radiotherapie $\cdot$ SIRT
}

\section{Zusammenfassung}

In den Leitlinien zur Behandlung verschiedener solider Tumoren wird die Metastasierung des Primärtumors nach wie vor als das systemische Stadium der Erkrankung definiert. Diese Definition begründet das Vorgehen für eine systemische Therapie. Interessanterweise, und trotz des Konzepts der systemischen Beteiligung, hat die chirurgische Resektion als lokale Behandlungsmöglichkeit langfristige Ergebnisse in einer Untergruppe von Patienten mit begrenzter Metastasierung zeigen können; dies bekräftigt das Konzept der oligometastatischen Erkrankung. Die Radiofrequenzablation hat günstige Ergebnisse bei Patienten mit Leberzellkarzinom und kolorektalen Metastasen gezeigt, und einige Studien weisen ihr prognostisches Potenzial bei mit systemischen Therapien kombinierten Behandlungen auf. Allerdings gelten hierbei einige wichtige technische Einschränkungen, wie z.B. Größenbeschränkung, "heat sink»-Effekte und unvorhersehbare Wärmeverteilung auf benachbarte Risikostrukturen. Interventionelle und nichtinvasive radiotherapeutische Techniken können diese Einschränkungen überwinden und hierdurch die Optionen für oligometastatische Patienten und für zytoreduktive Konzepte erweitern. Aktuelle Daten deuten auf sehr hohe lokale Kontrollraten auch bei großen Tumoren an jedem Ort im menschlichen Körper hin. Dieser Artikel befasst sich mit den Charakteristika und Möglichkeiten der stereotaktischen (Körper-)Radiotherapie, der interstitiellen hochdosierten Brachytherapie und der Yttrium-90-Radioembolisation. Wir diskutieren in diesem Beitrag die Unterschiede der technischen Präferenzen sowie ihre Auswirkungen auf die Indikationen. Aktuelle Daten werden vorgestellt und mit einem Fokus auf die Anwendung in oligometastatischen oder zytoreduktiven Konzepten bei unterschiedlichen Tumorbiologien diskutiert.

\section{KARGER \\ Fax +497614520714 \\ Information@Karger.com}

www.karger.com (c) 2014 S. Karger GmbH, Freiburg

$1662-6664 / 14 / 0304-0245 \$ 39.50 / 0$

Accessible online at:

www.karger.com/vim
Dr. med. Peter Hass

Klinik für Strahlentherapie

Universitätsklinikum Magdeburg AöR

Leipziger Straße 44, 39120 Magdeburg, Germany

peter.hass@med.ovgu.de 


\section{Introduction}

\section{The Concept}

Metastatic spread of the primary is still defined as the systemic stage of disease in treatment guidelines for various solid tumors. This definition is the rationale for systemic therapy whose effectiveness has evolved tremendously over the past decades due to the introduction of new substances and schemes and the implementation of antibody-including regimens $[1,2]$. However, the systemic effect(ivity) goes along with a systemic toxicity profile, which, on the one hand, hampers its applicability in comorbid patients. On the other hand, systemic treatments are often related to diminished quality of life [3-5]. Interestingly and despite the concept of systemic involvement, surgical resection as a local treatment has proven long-term outcomes in a subset of patients with limited metastatic disease [6-9]. In expansion of these data, the concept of oligometastatic disease has evolved, defined as a tumor pattern with limited metastatic spread in biologically favorable tumors in regard to growth dynamics, future systemic spread, and thus overall prognosis [10-12]. Furthermore, this concept of limited metastatic disease claims for local treatments beyond resection, keeping in mind that only a minority of patients are eligible for the surgical approach [13]. Beyond surgical resection, a long-term observational study of metastatic colorectal disease indicated impressive overall survival (OS) in unresectable patients treated with radiofrequency ablation (RFA) as compared to the published outcomes after surgery [14]. Some studies comparing patient cohorts undergoing RFA to surgery directly but non-randomized yielded inferior outcomes for the image-guided radiofrequency approach. However, most of these studies display a strong selection bias, and prospective randomized data comparing surgery and the image-guided approach is not available today [15-18]. In colorectal liver metastasis, the CLOCC trial revealed a significantly higher progression-free survival (PFS) in patients receiving RFA plus systemic chemotherapy versus systemic therapy alone in first-line treatment of metastatic colorectal cancer [19]. The study was not powered for survival. However, median survival was 45 months versus 40 months in favor of the combined treatment.

Some studies demonstrate similar local control rates following RFA or surgery in selected tumor entities (such as neuroendocrine carcinoma) [20,21]. In early and very early hepatocellular carcinoma (HCC), RFA is a suboptimal standard method [22]. Emerging evidence suggests that in small HCCs in cirrhotic patients image-guided percutaneous RFA even yields favorable OS similar or even favorable to resection $[23,24]$. In addition to such efforts reaching out to potentially curative treatment intentions, aggressive cytoreduction in advanced stages of metastatic gastrointestinal tumors applying locoregional treatments such as Yttrium-90 (Y90) radioembolization (RE) in combination with systemic treatments are under research (SIRFLOX, NCT00724503, SIR-STEP,
NCT01895257). Recent advances in invasive and non-invasive radiotherapeutic techniques, imaging, and integrated planning algorithms have opened a gate with remarkably expanded options towards which patients are technically applicable. The specific value of these methods as well as the proper indication still is under scrutiny.

\section{Local Non-Surgical Approaches: The Options}

In general, one may discriminate between thermal-physical (e.g. RFA, laser-induced thermal therapy (LITT)), chemical (transarterial embolisation (TAE), or transarterial chemoembolisation (TACE)) and radiooncological procedures (e.g. stereotactic body radiation therapy (SBRT), high-dose-rate (HDR) interstitial brachytherapy (iBT), and Y90-RE)) [2535]. RFA is currently the most frequently applied technique, foremost in non-resectable tumors of the liver and lung [3639]. Therefore, RFA is well described, but - as a thermal ablative method - it inheres some technical restrictions due to the tumor size and location [40, 41]. Radiotherapeutic techniques may overcome these limitations.

Radiation to liver tumors may be applied percutaneously by SBRT or cyberknife techniques [42]. HDR-iBT is a technique employing a point source, e.g. iridium-192 $\left({ }^{192} \mathrm{Ir}\right)$, delivered through catheters which have been implanted in the tumor under computed therapy (CT) guidance. The technique allows the delivery of excessive doses inside the target volume while saving adjacent structures from potentially harmful exposure due to favorable decay characteristics distant to the point source. It overcomes size limits and restrictions induced by tumor location, e.g. close proximity to the liver hilum or large vessels. It also overcomes constraints of percutaneous, non-invasive irradiation techniques by avoiding overexposure of the surrounding tissue while providing the opportunity to apply high doses to the tumor [29, 43-45].

Furthermore, in more advanced stages with hepatic dominant disease, Y90-RE (selective internal radiation therapy (SIRT)) is an alternative option to deliver a rather locoregional treatment in liver malignancies. This treatment is based on intra-arterial application of Y90 isotopes coupled to microspheres of distinct sizes, enabling their delivery into atypical tumor vessels rather than to arteries feeding regular liver parenchyma [46]. However, since the distribution of the particles always induces exposure of normal liver parenchyma as well, only patients with a preserved liver function are qualified, and distinctive preliminaries and tests to avoid undesired extrahepatic deposits of microspheres and deterioration of liver function are necessary.

\section{Radioablative Local Techniques}

\section{Stereotactic Radiotherapy (SRT) for Brain Tumors}

Especially during the last two decades, radiooncology has undergone tremendous advances by highly sophisticated irra- 
Fig. 1. Isodose lines: right hilar metastases of colorectal cancer, high dose coverage of tumor achieves an acceptable exposure to surrounding tissue (lung, heart).

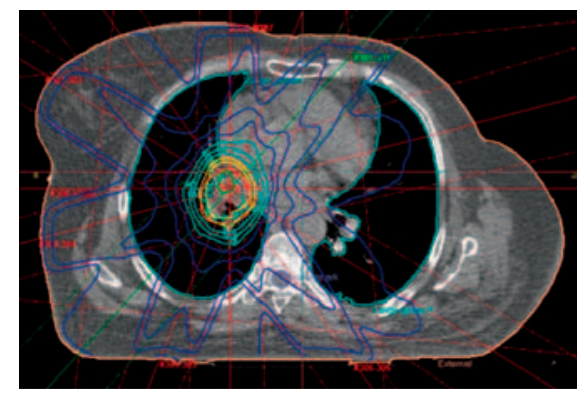

diation units as well as new soft- and hardware for calculation and conformal dose delivery. Implementation of three-dimensional stereotactic coordinate systems enable irradiation of small oligometastases with high single doses strictly respecting the limitations of surrounding normal tissue or adjacent risk structures. In most cases hypofractionated concepts with only a few radiation sessions are prescribed. Only recently the term radiosurgery has been introduced, describing the ability to achieve a local ablative impact with a single session.

Stereotactic radiosurgery has initially matured in the treatment of cerebral metastases or recurrent primary neoplasms (e.g. gliomas) or benign tumors (e.g. acoustic neuroma) as well as arteriovenous malformations [47]. Precondition is the fixation of the skull within a stereotactic frame [30] or special synthetic devices to model an individual stiff mask (BrainLab, Munich, Germany) [48].

\section{Stereotactic Body Radiation Therapy (SBRT)}

Significant improvement in local control due to cranial stereotaxis as well as initiation of image-guided radiotherapy (IGRT) and intensity-modulated radiotherapy (IMRT) triggered the transfer of this technique to extracranial indications as SBRT. The simple difference is that targets outside the brain often display significant motion, e.g. due to breathing, exemplified by liver and lung malignancies. Hence, the technical challenges are considerably higher in extracranial locations, and only in the past few years an increasing number of studies on SBRT of liver or lung treatments has demonstrated the increased expertise and reliability of this technique, although current data still varies in outcome measures [49-51]. Particularly in SBRT of lung malignancies, there are different techniques used to reduce breathing motion causing geometric instability of the clinical target volume (CTV). Most methods require a physical pressure device. Image guidance for gating and tracking and intensity beam modulation (IMRT) as well as modern calculation algorithms have improved accuracy significantly [52]. The MRI(magnetic resonance imaging)- or CT-based tumor definition (gross tumor volume (GTV)) gains an added safety margin, achieving the planning target volume (PTV) [52, 53]. The safety margin, which depends on the institutionally applied technique, is at least $5 \mathrm{~mm}$ in axial and $10 \mathrm{~mm}$ in craniocaudal orientation.

SBRT (like cranial SRT) permits precise irradiation. This enables the radiotherapist to lower the dose to adjacent risk structures or 'organs at risk' (OAR) significantly compared to conventional 3D-conformal radiotherapy, thus permitting ablative doses to the tumor. In liver neoplasms of different origins, 1-year local control rates between 71 and $95 \%$ have been reported [42]. In inoperable stage 1 non-small cell lung cancers of up to $5 \mathrm{~cm}$, a local control rate of $98 \%$ after 3 years was achieved in a multicenter study [54]. However, in contrast to irradiating inside out such as by brachytherapy (BT), the external application mode of SBRT leads to an exposure of large volumes of neighboring tissues to be exposed to considerable doses [55].

SBRT offers an effective treatment with a non-invasive approach, avoiding intervention-related complications like bleeding events. However, effective high radiation doses go along with significant exposure of normal surrounding tissue. This causes relatively strong restrictions with respect to size, number of lesions, and location. The balance between applying effective doses und safety concerns is sometimes difficult to find $[51,56]$. Published data on the safety of abdominal SBRT describes grade 3 and 4 events in a wide range of 0 to 78 and 0 to $25 \%$, respectively, including gastroduodenal ulcerations, hepatic toxicities, nausea/vomiting, esophagitis, and stenosis of the bile duct [55]. Radiation-induced liver disease seems to be less frequent compared to conventional liver radiotherapy [55] (fig. 1).

Brachytherapy: High-Dose-Rate Interstitial Brachytherapy

BT as a highly effective radiotherapy in various tumors has been conducted for more than 100 years in superficially located tumors or tumors accessible through natural orifices of the body as a contact or intracavitary BT. Sources used include palladium-103 $\left({ }^{103} \mathrm{Pd}\right)$, iodine-131 $\left({ }^{131} \mathrm{I}\right.$; low-dose-rate = LDR BT), or ${ }^{192} \mathrm{Ir}$ (HDR-BT). Besides the point source position, the dose rate determines the required length of the application to reach a prescribed target dose.

HDR-iBT is a radiation technique used in various locations inside the body, where a point source, e.g. ${ }^{192} \mathrm{Ir}$, is guided through interventionally implanted catheters into the tumor $[45,57-60]$. The implementation of this technique in parenchymal tumors was driven by the introduction of 3D planning systems based on CT or magnetic resonance tomography volume data sets and the development of CT and MR fluoroscopy from the nineties as well as early years of the 21st century.

It provides advantages compared to percutaneous irradiation by applying higher doses inside the target volume while saving surrounding parenchyma from unnecessary exposure more sufficiently. Positioning of the BT catheters is accomplished either by fluoroscopy CT or by real-time fluoroscopic MRI. The catheter position, the tumor margin, and the anatomic risk structures are verified by contrast-enhanced images sent to the treatment planning unit.

Limitations of SBRT have been demonstrated in previous studies, such as a limited number of reasonably treatable me- 
Fig. 2. a Two hypointensed metastases in MRI with primovist; $\mathbf{b}$ final scan with catheters (white lines) within the tumor; c same scan with tumor-surrounding isodoses, showing sufficient coverage.

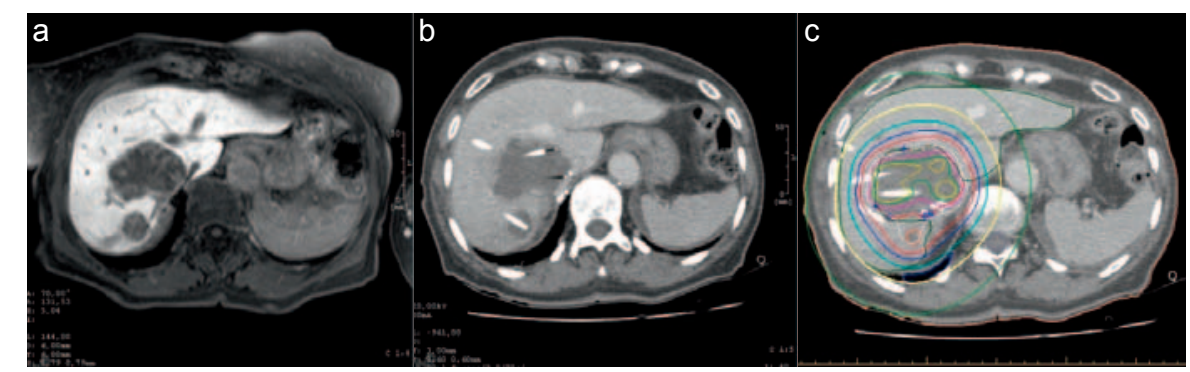

tastases or a safe lesion diameter up to $4-5 \mathrm{~cm}[51,56]$. Beyond that size threshold, local tumor control rates after SBRT tend to decrease significantly [61, 62]. In contrast, CT-guided BT seems to deliver more reliable tumor control even in very large lesions. In previous studies, local tumor control in HCC up to $12 \mathrm{~cm}$ was $90 \%$ at 1 year. In a randomized controlled dose escalation study on colorectal cancer, local control of liver metastases after iBT was $>90 \%$ if a minimum threshold dose (with dramatic dose escalation in the CTV) of 20 Gy was applied in tumors up to $15 \mathrm{~cm}[43,45]$. In addition, repetitive BT has proven to not enhance the procedural or post-therapeutic risk [63]. In pulmonary malignancies of different origins and a tumor diameter of up to $11 \mathrm{~cm}$, a 1-year local control rate of $91 \%$ was achieved with single doses between 15 and $20 \mathrm{~Gy}$ [44]. iBT is commonly performed in a single session even in larger tumor volumes of up to $10 \mathrm{~cm}$ in diameter and more, applying minimal doses inside the CTV of 15-25 Gy (however, inside the target, the doses will be extensively higher the closer the position to the point source or catheter is). High single doses exceeding $8-10 \mathrm{~Gy} /$ fraction (as it is also the case in SBRT, if applicable) seem to trigger additional radiobiological phenomena beyond direct cell killing, hence probably boosting the treatment effect, e.g. inducing apoptosis to the vascular endothelium $[64,65]$. This enables the interventional oncologist to treat even large and centrally located liver lesions effectively [58, 66]. Triggering breath or body motion is not necessary since the tumor is fixed by the implanted catheters guiding the point source during treatment. Hypofractionated schemes with two or three fractions are sometimes helpful in locations close to the stomach or duodenum, the cutis, or in very large tumors.

One drawback of iBT is its invasiveness compared to SBRT. However, the frequency of adverse events related to the interventional applicator implantation is still low with bleedings requiring treatment (either transfusion or embolization) amounting to $4 \%$ in HCC and to $2.5 \%$ in colorectal liver metastases $[43,45]$. In pulmonary interventions, minor and major pneumothoraxes were observed in 12 and $2 \%$, respectively [44]. The probability of radiation-induced liver disease (RILD) development seems to be very low even after the treatment of very large liver tumors in cirrhosis [43, 45]. Gastroduodenal ulcerations occur seldom after exposure of the gastric or duodenal mucosa to more than 14 Gy [67] (fig. 2).

\section{Y90 Radioembolization}

RE using Y90 microspheres is a relatively new modality applicable for use even in patients with extensive liver involvement of primary and secondary liver neoplasms. Recent experience indicates the efficacy of RE in patients with a tumor load up to $50 \%$ or diffuse location $[32,68-70]$. However, there still is a lack of evidence from randomized controlled trials such as published on systemic chemotherapies or TACE (only HCC) [25, 71]. Therefore, RE is frequently placed at the end of a therapeutic algorithm after the failure of conventional therapies. In this regard, RE is seen as an exceptional salvage treatment usually conducted at just one time-point per patient. The absence of alternative treatment options after an initial RE raises the question whether a repeated RE would be safe and effective. In individual patients the indication for repeated RE may vary between treatment indications for one or both liver lobes. Safety is of considerable interest in patients with a restricted liver function after previous RE, possibly in combination with hepatotoxic chemotherapies or liver cirrhosis. RE comprises the injection of radioactive either Y90-labelled resin microspheres (SIRSpheres $^{\circledR}$; Sirtex Medical, Lane Cove, Australia) or Y90-labelled glass spheres (TheraSphere ${ }^{\circledR}$; BTG, London, UK) into the arterial hepatic circulation. The spheres are designed to accumulate specifically in tumor tissue due to the dual liver blood supply. Anti-tumor efficacy is linked to the beta radiation from Y90 which decays with a physical half-life of $64 \mathrm{~h}$ (approximately 2.7 days). Prior to RE, an angiography of the celiac trunk is performed, usually including coil embolization of the gastroduodenal artery and right gastric artery to avoid extrahepatic accumulation of microspheres. After coil embolization, injection of Tc99m-MAA (Technetium-99m bound to macro-aggregated albumin) into the hepatic artery is performed to rule out a relevant shunt volume to the lung or extra-hepatic accumulation (e.g. stomach). Therapy with active spheres is performed as total liver irradiation or, to better preserve liver function, sequentially in two separate procedures for the right and left liver lobes at an interval of 4-6 weeks, assuming that both liver lobes are involved.

There is evidence for the effectiveness of RE in cancer patients with more or less extensive liver involvement. For salvage $R E$ in colorectal liver metastases, OS of 14.5 months [72], 10.5 months [73], and 10 months [74] have been reported. 
Fig. 3. Angiography of the left hepatic artery documenting the intra-arterial RE with Y90 microspheres (left); postprocedural 'Bremsstrahlen' szintigraphy conforming the deposit in the left liver lobe (right).

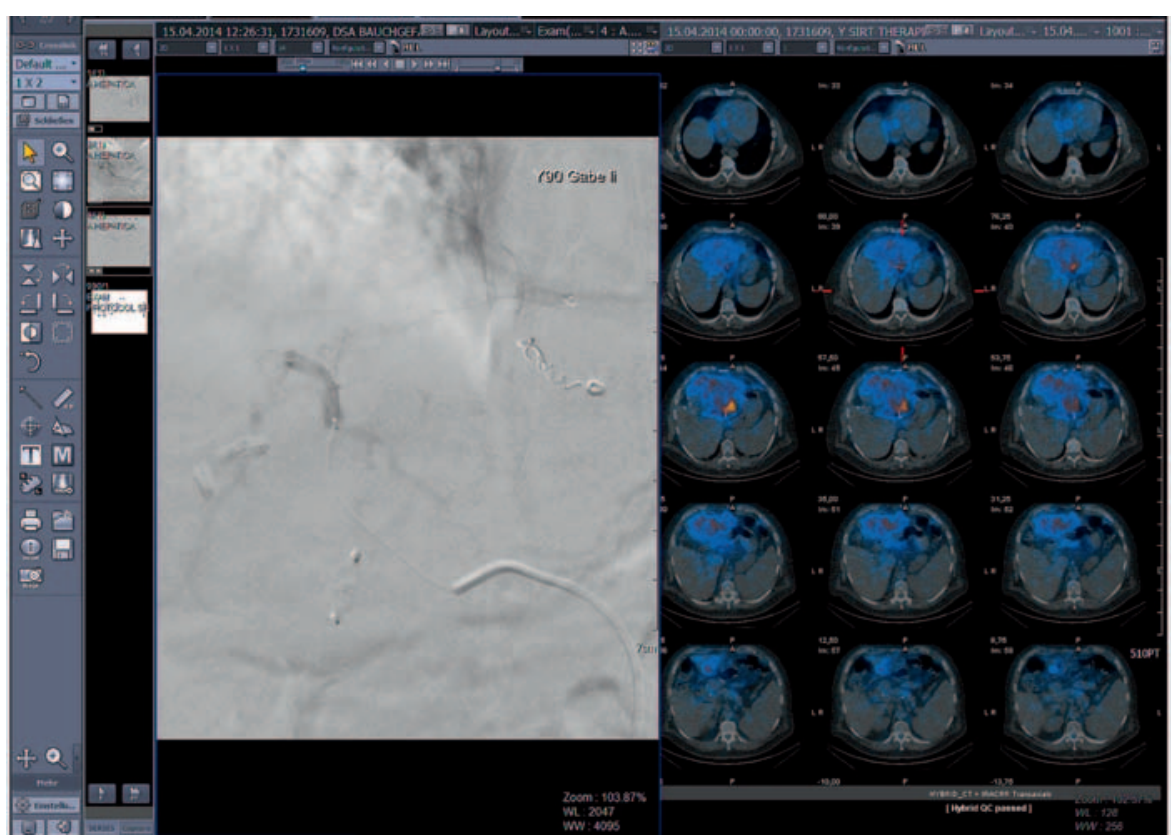

Seidensticker et al. [75] showed the superiority of RE over best supportive care for salvage colorectal liver metastases in a matched-pair analysis.

These results are noteworthy, especially when compared to systemic treatment in the second- to third-line setting. In a second-line situation, a FOLFIRI regimen in 213 patients resulted in a PFS of 5.1 months [76]. In a third-line situation, bevacizumab plus FOLFIRI or FOLFOX resulted in a PFS and OS of 5.3 and 9.5 months, respectively [77]. Adverse events in the aforementioned trial included grade 3-4 neutropenia in approximately $43 \%$, fatigue in $22 \%$, neuropathy in $22 \%$, and mucositis in $22 \%$ of all patients.

In $\mathrm{HCC}$, present data suggests that RE is best placed after TACE failure in the intermediate stage (EASL/EORTC guidelines) or in patients with diffuse ( $>4$ tumors) or large tumors $(>5 \mathrm{~cm})[32,78]$. Salem et al. [79] reported an OS of 17.2 and 7.7 months for 291 patients with HCC, depending on the Child-Pugh stage (A or B). The most apparent difference to TACE, however, is the fact that TACE has evolved as a repetitive procedure which is not the case for RE. Despite the fact that the effect of RE vanishes over time, RE has been adopted as a single therapeutic approach, although there is some evidence that repetitive RE is safe based on patient selection and when certain preconditions such as preserved liver function are met $[70,80]$. In addition to HCC, the next most common indications for RE are colorectal cancer, breast cancer, and neuroendocrine liver metastases [81].

Despite combination schemes, RE offers a rather short treatment time in contrast to systemic treatments, which continue over weeks. Most common side effects include grade 1-2 fatigue in up to $40 \%$ during the first 2 weeks after treatment or mild nausea during the first few days. Severe complications are rare and include gastric ulcer $(<3 \%)$ by accidental implantation of spheres in the gastric mucosa, or RILD due to overexposure of functional liver parenchyma. The incidence varies depending on patient selection, preventive measures, and dosimetry (normally $<5 \%$; up to $20 \%$ in high-risk patients) [69, 82-84] (fig. 3).

\section{Discussion}

Various local treatment approaches claim a curative potential in limited metastasized stages of various tumors, ultimately basing upon the concept of oligometastatic disease [10-12]. The strongest evidence today exists for the resection of liver metastases [6-9]. However, non-surgical methods such as thermal ablation and radiotherapeutic approaches have been introduced recently, essentially targeting patients not eligible for surgery. This evolution will potentially have a major impact on patient management and outcome - one should bear in mind that most patients with metastatic gastrointestinal tumors present with unresectable disease. The proof of equality compared to surgery should therefore not be the mainstay of clinical interest or prospective study protocols, although it has already been proven for selected indications (e.g. RFA in HCC). In the majority of patients, resection or ablation are not competitive but rather complementary. Given the local control rates of image-guided ablation as compared to $\mathrm{R} 1$ resection rates, e.g. in liver metastases of colorectal cancer, most likely a mentality allocating the more curative intention to surgery and the more palliative intention to local ablation will help guiding patient selection. The difficulty of the concept of oligometastatic disease, however, is the discrimination between patients with oligometastatic 'phenotype' but undiscovered polymetastatic nature and those who 
Fig. 4. a HCC, left lobe segment III, iBT; sufficient isodose covering CTV, low whole liver exposition due to steep dose drop-off of the ${ }^{192}$ Ir source; b same case; virtual SBRT calculation, with dose-volume histogram showing different exposure of the whole liver.
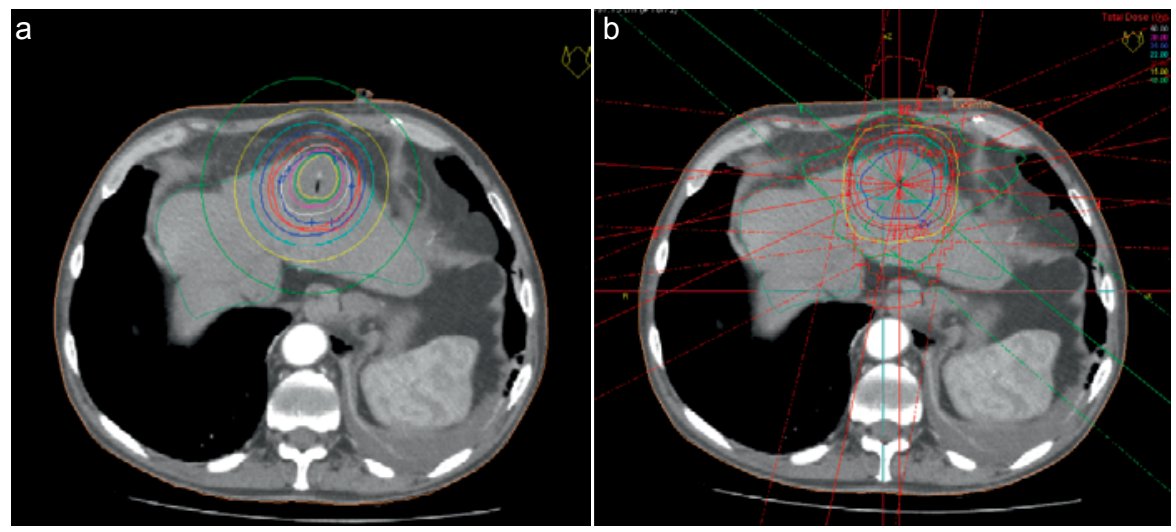

are 'truly' oligometastatic with a rather benign tumor biology. Tumor markers, gene expression profiles, or mutational status are yet to be identified to help in aiding therapeutic decisions for local treatment of metastasized patients [85].

There is increasing evidence that radiotherapeutic techniques in parenchymatous and glandular organs, lymph nodes, and soft tissues are effective, tumoricidal treatments beyond the technical capabilities of thermal ablation such as RFA [11, 61, 64, 75, 86-90]. To some extent, as well as differentially, SBRT, iBT, und RE overcome the limitations of RFA as the most commonly used local ablative technique worldwide with respect to size, location, and number of lesions treated [40, 41]. As a consequence, the spectrum of non-surgical ablative methods is expanded and the indications are widened. SBRT as well as iBT offer highly precise conformal radiation and therefore enable the application of radiosurgical doses to a wide range of neoplastic appearances. Concurrently, both methods allow a reduced exposition of the surrounding and adjacent tissue or structures (e.g. intestinal mucosa), consequentially avoiding an overexposure of adjacent normal tissue and risk structures. The hypofractionation with doses above 8-10 Gy (high single doses) evoke radiobiological effects beyond mitotic cell death like apoptosis to the vascular endothelium, therefore facilitating radioablation [64, 65]. An advantage of high-dose single-fraction SBRT is its non-invasiveness without potential intervention-related hazards such as bleeding events, occurring still seldom in interstitial BT. In contrast, iBT overcomes limitations of SBRT with respect to size and location $[43,45,58,66]$. Therefore, we suggest that the stratification of patients to receive SBRT or iBT might follow the rule that in single lesions up to $5 \mathrm{~cm}$ SBRT should be applied, whereas in larger or multiple lesions iBT may facilitate a more reliable tumor control. In more advanced cases, RE will probably be the method of choice [75].

Stratification for either local radiotherapeutic treatments or RE will most likely be based on the total number of lesions, enabling treatment in a reasonable period of time [91] (fig. 4).

At present, Y90-RE is the only radioablative method for diffuse liver metastases. Today it is usually prescribed in sal- vage patients. This restriction to salvage may be overcome once SIRFLOX trial results are published. In this particular trial, RE is combined with FOLFOX and Avastin in the firstline treatment of multifocal, irresectable colorectal liver metastases. Patient recruitment has been completed, and first results are expected by the end of 2014. The SIR-step trial is recruiting and compares Y90-RE plus systemic maintenance therapy versus maintenance therapy alone after successful induction systemic therapy. In $\mathrm{HCC}$, the only current prospective randomized study design considering repetitive treatments in intermediate and advanced stage HCC is SORAMIC, which is considered to continue recruitment until mid-2015/2016. Preliminary safety data is already available [82].

\section{Conclusion}

Radiation therapy offers considerable contributions to the multimodal management of solid tumors not only in the standard palliative setting but also in a curative intention by applying radioablative approaches such as SBRT or CTguided BT. In oncological terms, the question to be answered today is not whether a local tumor ablation can technically be managed, but which patient is benefitting from such a therapy and how should the overall treatment concept including systemic approaches look like. Better understanding of the oligometastatic concept and identification of according biomarkers would dramatically benefit patients with metastases of gastrointestinal or other tumors. Ultimately, best patient care can be offered in institutions supplying a large tool box including open and laparoscopic surgery, image-guided ablation by thermal or radiation methods, locoregional approaches such as RE or TACE, as well as systemic chemotherapy options - and most importantly, experience on the best sequence and combination of such methods with systemic treatments.

\section{Disclosure Statement}

No potential conflict of interest. 


\section{References}

1 Amit L, Ben-Aharon I, Vidal L, Leibovici L, Stemmer S: The impact of Bevacizumab (Avastin) on survival in metastatic solid tumors - a meta-analysis and systematic review. PLoS One 2013;8:e51780.

2 Iacovelli R, Alesini D, Palazzo A, et al: Targeted therapies and complete responses in first line treatment of metastatic renal cell carcinoma. A metaanalysis of published trials. Cancer Treat Rev 2014; 40:271-275.

3 Herman JM, Narang AK, Griffith KA, et al: The quality-of-life effects of neoadjuvant chemoradiation in locally advanced rectal cancer. Int J Radiat Oncol Biol Phys 2013;85:e15-e19.

4 Hunter KU, Schipper M, Feng FY, et al: Toxicities affecting quality of life after chemo-IMRT of oropharyngeal cancer: prospective study of patientreported, observer-rated, and objective outcomes. Int J Radiat Oncol Biol Phys 2013;85:935-940.

$\checkmark 5$ Funaioli C, Longobardi C, Martoni AA: The impact of chemotherapy on overall survival and quality of life of patients with metastatic colorectal cancer: a review of phase III trials. J Chemother 2008; 20:14-27.

6 Fong Y, Cohen AM, Fortner JG, et al: Liver resection for colorectal metastases. J Clin Oncol 1997; 15:938-946.

7 Kopetz S, Chang GJ, Overman MJ, et al: Improved survival in metastatic colorectal cancer is associated with adoption of hepatic resection and improved chemotherapy. J Clin Oncol 2009;27:3677-3683.

$>8$ Robertson DJ, Stukel TA, Gottlieb DJ, Sutherland JM, Fisher ES: Survival after hepatic resection of colorectal cancer metastases: a national experience. Cancer 2009;115:752-759.

$\checkmark$ Simmonds PC, Primrose JN, Colquitt JL, Garden OJ, Poston GJ, Rees M: Surgical resection of hepatic metastases from colorectal cancer: a systematic review of published studies. Br J Cancer 2006; 94:982-999.

10 Palma DA, Salama JK, Lo SS, et al: The oligometastatic state-separating truth from wishful thinking. Nat Rev Clin Oncol 2014;DOI: 10.1038/nrclinonc. 2014.96.

11 Badakhshi H, Grun A, Stromberger C, Budach V, Boehmer D: Oligometastases: the new paradigm and options for radiotherapy. A critical review. Strahlenther Onkol 2013;189:357-362.

12 Weichselbaum RR, Hellman S: Oligometastases revisited. Nat Rev Clin Oncol 2011;8:378-382.

13 Germer CT: Hepatic metastases: an interdisciplinary therapy approach is desirable (article in German). Chirurg 2010;81:505-506.

14 van Tilborg AA, Meijerink MR, Sietses C, et al: Long-term results of radiofrequency ablation for unresectable colorectal liver metastases: a potentially curative intervention. Br J Radiol 2011;84:556-565.

15 Nahum GS, Dupuy DE: Image-guided radiofrequency tumor ablation: challenges and opportunities - part I. J Vasc Interv Radiol 2001;12:1021-1032.

16 Nakazawa T, Kokubu S, Shibuya A, et al: Radiofrequency ablation of hepatocellular carcinoma: correlation between local tumor progression after ablation and ablative margin. AJR Am J Roentgenol 2007;188:480-488.

17 Berber E, Pelley R, Siperstein AE: Predictors of survival after radiofrequency thermal ablation of colorectal cancer metastases to the liver: a prospective study. J Clin Oncol 2005;23:1358-1364.

18 Pawlik TM, Izzo F, Cohen DS, Morris JS, Curley SA: Combined resection and radiofrequency ablation for advanced hepatic malignancies: results in 172 patients. Ann Surg Oncol 2003;10:1059-1069.
19 Ruers T, Punt C, van CF, et al: Radiofrequency ablation combined with systemic treatment versus systemic treatment alone in patients with non-resectable colorectal liver metastases: a randomized EORTC Intergroup phase II study (EORTC 40004). Ann Oncol 2012;23:2619-2626.

20 Gillams A, Cassoni A, Conway G, Lees W: Radiofrequency ablation of neuroendocrine liver metastases: the Middlesex experience. Abdom Imaging 2005:30:435-441.

21 Lu MD, Kuang M, Liang LJ, et al: Surgical resection versus percutaneous thermal ablation for earlystage hepatocellular carcinoma: a randomized clinical trial (article in Chinese). Zhonghua Yi Xue Za Zhi 2006;86:801-805.

22 Lencioni R: Loco-regional treatment of hepatocellular carcinoma. Hepatology 2010;52:762-773.

23 Duan C, Liu M, Zhang Z, Ma K, Bie P: Radiofrequency ablation versus hepatic resection for the treatment of early-stage hepatocellular carcinoma meeting Milan criteria: a systematic review and meta-analysis. World J Surg Oncol 2013;11:190.

24 Cucchetti A, Piscaglia F, Cescon M, et al: An explorative data-analysis to support the choice between hepatic resection and radiofrequency ablation in the treatment of hepatocellular carcinoma. Dig Liver Dis 2014;46:257-263.

25 Bruix J, Sala M, Llovet JM: Chemoembolization for hepatocellular carcinoma. Gastroenterology 2004;127:S179-S188.

26 Clark TW: Chemical ablation of liver cancer. Tech Vasc Interv Radiol 2007;10:58-63.

27 Okunieff P, Petersen AL, Philip A, et al: Stereotactic Body Radiation Therapy (SBRT) for lung metastases. Acta Oncol 2006;45:808-817.

28 Pech M, Wieners G, Kryza R, et al: CT-guided brachytherapy (CTGB) versus interstitial laser ablation (ILT) of colorectal liver metastases: an intraindividual matched-pair analysis. Strahlenther Onkol 2008;184:302-306.

29 Ricke J, Wust P, Wieners G, et al: Liver malignancies: CT-guided interstitial brachytherapy in patients with unfavorable lesions for thermal ablation. J Vasc Interv Radiol 2004;15:1279-1286.

30 Ricke J, Wust P, Stohlmann A, et al: CT-guided interstitial brachytherapy of liver malignancies alone or in combination with thermal ablation: phase I-II results of a novel technique. Int J Radiat Oncol Biol Phys 2004;58:1496-1505.

31 Salem R, Lewandowski RJ, Atassi B, et al: Treatment of unresectable hepatocellular carcinoma with use of $90 \mathrm{Y}$ microspheres (TheraSphere): safety, tumor response, and survival. J Vasc Interv Radiol 2005;16:1627-1639.

32 Salem R, Lewandowski RJ, Kulik L, et al: Radioembolization results in longer time-to-progression and reduced toxicity compared with chemoembolization in patients with hepatocellular carcinoma. Gastroenterology 2011;140:497-507.

33 Vogl TJ, Straub R, Eichler K, Sollner O, Mack MG: Colorectal carcinoma metastases in liver: laser-induced interstitial thermotherapy - local tumor control rate and survival data. Radiology 2004;230:450-458.

34 Wurm RE, Gum F, Erbel S, et al: Image guided respiratory gated hypofractionated Stereotactic Body Radiation Therapy (H-SBRT) for liver and lung tumors: initial experience. Acta Oncol 2006; 45:881-889.

35 Yin FF, Das S, Kirkpatrick J, Oldham M, Wang Z, Zhou SM: Physics and imaging for targeting of oligometastases. Semin Radiat Oncol 2006;16:85-101.
36 Bleicher RJ, Allegra DP, Nora DT, Wood TF, Foshag LJ, Bilchik AJ: Radiofrequency ablation in 447 complex unresectable liver tumors: lessons learned. Ann Surg Oncol 2003;10:52-58.

37 Curley SA, Izzo F: Radiofrequency ablation of primary and metastatic hepatic malignancies. Int J Clin Oncol 2002;7:72-81.

38 Lee DH, Lee JM, Lee JY, et al: Radiofrequency ablation of hepatocellular carcinoma as first-line treatment: long-term results and prognostic factors in 162 patients with cirrhosis. Radiology 2014;270: 900-909.

39 Weis S, Franke A, Mossner J, Jakobsen JC, Schoppmeyer K: Radiofrequency (thermal) ablation versus no intervention or other interventions for hepatocellular carcinoma. Cochrane Database Syst Rev 2013;12:CD003046.

40 Kunzli BM, Abitabile P, Maurer CA: Radiofrequency ablation of liver tumors: actual limitations and potential solutions in the future. World $\mathrm{J}$ Hepatol 2011;3:8-14

41 Rhim H, Lim HK: Radiofrequency ablation of hepatocellular carcinoma: pros and cons. Gut Liver 2010;4(suppl 1):S113-S118.

42 Scorsetti M, Clerici E, Comito T: Stereotactic body radiation therapy for liver metastases. J Gastrointest Oncol 2014;5:190-197.

43 Mohnike K, Wieners G, Schwartz F, et al: Computed tomography-guided high-dose-rate brachytherapy in hepatocellular carcinoma: safety, efficacy, and effect on survival. Int J Radiat Oncol Biol Phys 2010;78:172-179.

44 Peters N, Wieners G, Pech M, et al: CT-guided interstitial brachytherapy of primary and secondary lung malignancies: results of a prospective phase II trial. Strahlenther Onkol 2008;184:296-301.

45 Ricke J, Mohnike K, Pech M, et al: Local response and impact on survival after local ablation of liver metastases from colorectal carcinoma by computed tomography-guided high-dose-rate brachytherapy. Int J Radiat Oncol Biol Phys 2010;78:479-485.

46 Kennedy AS, Nutting C, Coldwell D, Gaiser J, Drachenberg C: Pathologic response and microdosimetry of (90)Y microspheres in man: review of four explanted whole livers. Int J Radiat Oncol Biol Phys 2004;60:1552-1563.

47 Porter RW, Detwiler PW, Han PP, Spetzler RF: Stereotactic radiosurgery for cavernous malformations: Kjellberg's experience with proton beam therapy in 98 cases at the Harvard Cyclotron. Neurosurgery 1999;44:424-425.

48 Alheit H, Dornfeld S, Dawel M, et al: Patient position reproducibility in fractionated stereotactically guided conformal radiotherapy using the BrainLab mask system. Strahlenther Onkol 2001;177:264-268.

49 Navarria P, Ascolese AM, Tomatis S, et al: Stereotactic body radiotherapy (SBRT) in lung oligometastatic patients: role of local treatments. Radiat Oncol 2014;9:91.

50 Schefter TE, Kavanagh BD: Radiation therapy for liver metastases. Semin Radiat Oncol 2011;21:264 270.

51 Scorsetti M, Arcangeli S, Tozzi A, et al: Is stereotactic body radiation therapy an attractive option for unresectable liver metastases? A preliminary report from a phase 2 trial. Int J Radiat Oncol Biol Phys 2013;86:336-342.

52 Guckenberger M, Krieger T, Richter A, et al: Potential of image-guidance, gating and real-time tracking to improve accuracy in pulmonary stereotactic body radiotherapy. Radiother Oncol 2009;91: 288-295. 
53 Rusthoven KE, Kavanagh BD, Cardenes H, et al: Multi-institutional phase I/II trial of stereotactic body radiation therapy for liver metastases. J Clin Oncol 2009;27:1572-1578.

54 Timmerman R, Paulus R, Galvin J, et al: Stereotactic body radiation therapy for inoperable early stage lung cancer. JAMA 2010;303:1070-1076.

55 Thomas TO, Hasan S, Small W Jr, et al: The tolerance of gastrointestinal organs to stereotactic body radiation therapy: what do we know so far? J Gastrointest Oncol 2014;5:236-246.

56 Dawson LA: Overview: Where does radiation therapy fit in the spectrum of liver cancer local-regional therapies? Semin Radiat Oncol 2011;21:241-246.

57 Collettini F, Singh A, Schnapauff D, et al: Computed-tomography-guided high-dose-rate brachytherapy (CT-HDRBT) ablation of metastases adjacent to the liver hilum. Eur J Radiol 2013;82:e509e514.

58 Collettini F, Schnapauff D, Poellinger A, et al: Hepatocellular carcinoma: computed-tomographyguided high-dose-rate brachytherapy (CT-HDRBT) ablation of large $(5-7 \mathrm{~cm})$ and very large $(>7 \mathrm{~cm})$ tumours. Eur Radiol 2012;22:1101-1109.

59 Zamboglou N, Tselis N, Baltas D, et al: High-doserate interstitial brachytherapy as monotherapy for clinically localized prostate cancer: treatment evolution and mature results. Int J Radiat Oncol Biol Phys 2013;85:672-678.

60 Tselis N, Ferentinos K, Kolotas C, et al: Computed tomography-guided interstitial high-dose-rate brachytherapy in the local treatment of primary and secondary intrathoracic malignancies. J Thorac Oncol 2011;6:545-552.

61 Kirkpatrick JP, Kelsey CR, Palta M, et al: Stereotactic body radiotherapy: a critical review for nonradiation oncologists. Cancer 2014;120:942-954.

62 Dawood O, Mahadevan A, Goodman KA: Stereotactic body radiation therapy for liver metastases. Eur J Cancer 2009;45:2947-2959.

63 Ruhl R, Ludemann L, Czarnecka A, et al: Radiobiological restrictions and tolerance doses of repeated single-fraction HDR-irradiation of intersecting small liver volumes for recurrent hepatic metastases. Radiat Oncol 2010;5:44.

64 Brown JM, Koong AC: High-dose single-fraction radiotherapy: exploiting a new biology? Int J Radiat Oncol Biol Phys 2008;71:324-325.

65 Garcia-Barros M, Paris F, Cordon-Cardo C, et al: Tumor response to radiotherapy regulated by endothelial cell apoptosis. Science 2003;300:1155-1159.

-66 Tselis N, Chatzikonstantinou G, Kolotas C, Milickovic $\mathrm{N}$, Baltas D, Zamboglou N: Computed tomography-guided interstitial high dose rate brachytherapy for centrally located liver tumours: a single institution study. Eur Radiol 2013;23:2264-2270.
67 Streitparth F, Pech M, Bohmig M, et al: In vivo assessment of the gastric mucosal tolerance dose after single fraction, small volume irradiation of liver malignancies by computed tomographyguided, high-dose-rate brachytherapy. Int J Radiat Oncol Biol Phys 2006;65:1479-1486.

68 Garrean S, Muhs A, Bui JT, et al: Complete eradication of hepatic metastasis from colorectal cancer by Yttrium-90 SIRT. World J Gastroenterol 2007; 13:3016-3019.

69 Seidensticker R, Seidensticker M, Damm R, et al: Hepatic toxicity after radioembolization of the liver using (90)Y-microspheres: sequential lobar versus whole liver approach. Cardiovasc Intervent Radiol 2012;35:1109-1118.

70 Zarva A, Mohnike K, Damm R, et al: Safety of repeated radioembolizations in patients with advanced primary and secondary liver tumors and progressive disease after first selective internal radiotherapy. J Nucl Med 2014;55:360-366.

71 Llovet JM, Real MI, Montana X, et al: Arterial embolisation or chemoembolisation versus symptomatic treatment in patients with unresectable hepatocellular carcinoma: a randomised controlled trial. Lancet 2002;359:1734-1739.

72 Mulcahy MF, Lewandowski RJ, Ibrahim SM, et al: Radioembolization of colorectal hepatic metastases using yttrium-90 microspheres. Cancer 2009; 115:1849-1858.

73 Jakobs TF, Hoffmann RT, Dehm K, et al: Hepatic yttrium-90 radioembolization of chemotherapy-refractory colorectal cancer liver metastases. J Vasc Interv Radiol 2008;19:1187-1195.

74 Sato KT, Lewandowski RJ, Mulcahy MF, et al: Unresectable chemorefractory liver metastases: radioembolization with 90Y microspheres - safety, efficacy, and survival. Radiology 2008;247:507-515.

75 Seidensticker R, Denecke T, Kraus P, et al: Matched-pair comparison of radioembolization plus best supportive care versus best supportive care alone for chemotherapy refractory liver-dominant colorectal metastases. Cardiovasc Intervent Radiol 2012;35:1066-1073.

76 Muro K, Boku N, Shimada Y, et al: Irinotecan plus S-1 (IRIS) versus fluorouracil and folinic acid plus irinotecan (FOLFIRI) as second-line chemotherapy for metastatic colorectal cancer: a randomised phase $2 / 3$ non-inferiority study (FIRIS study). Lancet Oncol 2010;11:853-860.

77 Kang BW, Kim TW, Lee JL, et al: Bevacizumab plus FOLFIRI or FOLFOX as third-line or later treatment in patients with metastatic colorectal cancer after failure of 5-fluorouracil, irinotecan, and oxaliplatin: a retrospective analysis. Med Oncol 2009;26:32-37.
78 Hu HT, Kim JH, Lee LS, et al: Chemoembolization for hepatocellular carcinoma: multivariate analysis of predicting factors for tumor response and survival in a 362-patient cohort. J Vasc Interv Radiol 2011;22:917-923.

79 Salem R, Lewandowski RJ, Mulcahy MF, et al: Radioembolization for hepatocellular carcinoma using Yttrium-90 microspheres: a comprehensive report of long-term outcomes. Gastroenterology 2010;138:52-64.

80 Lam MG, Louie JD, Iagaru AH, Goris ML, Sze DY: Safety of repeated yttrium-90 radioembolization. Cardiovasc Intervent Radiol 2013;36:1320-1328.

81 Kennedy A: Radioembolization of hepatic tumors. J Gastrointest Oncol 2014;5:178-189.

82 Ricke J, Bulla K, Kolligs F, et al: Safety and toxicity of radioembolization plus Sorafenib in advanced hepatocellular carcinoma (HCC): analysis of the European multicenter trial SORAMIC. Liver Int 2014;DOI: 10.1111/liv.12622.

83 Sangro B, Gil-Alzugaray B, Rodriguez J, et al: Liver disease induced by radioembolization of live tumors: description and possible risk factors. Cancer 2008;112:1538-1546.

84 Sangro B, Bilbao JI, Boan J, et al: Radioembolization using 90Y-resin microspheres for patients with advanced hepatocellular carcinoma. Int J Radiat Oncol Biol Phys 2006;66:792-800.

85 Lussier YA, Khodarev NN, Regan K, et al: Oligoand polymetastatic progression in lung metastasis(es) patients is associated with specific microRNAs. PLoS One 2012;7:e50141.

86 Bignardi M, Navarria P, Mancosu P, et al: Clinical outcome of hypofractionated stereotactic radiotherapy for abdominal lymph node metastases. Int J Radiat Oncol Biol Phys 2011;81:831-838.

87 Dawood O, Mahadevan A, Goodman KA: Stereotactic body radiation therapy for liver metastases. Eur J Cancer 2009;45:2947-2959.

88 Ricke J, Wust P: Computed tomography-guided brachytherapy for liver cancer. Semin Radiat Oncol 2011;21:287-293.

89 Timmerman R, Paulus R, Galvin J, et al: Stereotactic body radiation therapy for inoperable early stage lung cancer. JAMA 2010;303:1070-1076.

90 Kennedy AS, McNeillie P, Dezarn WA, et al: Treatment parameters and outcome in 680 treatments of internal radiation with resin $90 \mathrm{Y}$-microspheres for unresectable hepatic tumors. Int J Radiat Oncol Biol Phys 2009;74:1494-1500.

91 Bester L, Meteling B, Boshell D, Chua TC, Morris DL: Transarterial chemoembolisation and radioembolisation for the treatment of primary liver cancer and secondary liver cancer: a review of the literature. J Med Imaging Radiat Oncol 2014;58: 341-352. 